\title{
Interactive Response Technology User Specification
}

National Cancer Institute

\section{Source}

National Cancer Institute. Interactive Response Technology User Specification. NCI

Thesaurus. Code C115592.

A detailed description of the requirements by the end user for the use of interactive response technology. 